\title{
Opinions on Obesity, Nutrition, and Basal Metabolic Rates
}

ISSN: 2577-1914

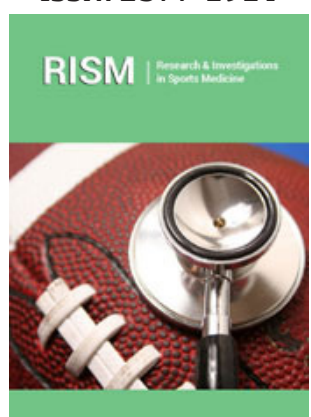

*Corresponding author: Qeleshi Anesti, Sport University of Tirana, Albania

Submission: 侮July 10, 2020

Published: 眥September 28, 2020

Volume 7 - Issue 1

How to cite this article: Qeleshi Anesti, Ikonomi Edison. Opinions on Obesity, Nutrition, and Basal Metabolic Rates. Res InvesSports Med,7(1),RISM.000655.2020. DOI: 10.31031/RISM.2020.07.000655

Copyright@ Qeleshi Anesti, This article is distributed under the terms of the Creative Commons Attribution 4.0 International License, which permits unrestricted use and redistribution provided that the original author and source are credited.

\author{
Qeleshi Anesti* and Ikonomi Edison \\ Sport University of Tirana, Albania
}

\begin{abstract}
Being overweight or obese is one thing, but childhood obesity is another thing altogether. Everything around you are different, even yourself. The entire picture becomes clearer when you have your own experience-when you yourself have been an obese child. Memories come and seem that you are looking at yourself in a film. A long movie playing your past, all for you. As per the ancient Balkan mentality, overweight/obesity is a sign of wellness and wealth, and this is true in some families. The way that they eat, love, drink, and celebrate is sometimes connected with being prosperous and being "healthy." Some centuries ago, a woman had to be overweight/obese to be considered beautiful. In "The Epic of the Kreshniks," (Albanian mythology) being beautiful, especially for women, means being big and fat. The mythical hero Muji needed to marry the biggest and the fattest woman in the district (Epic of Kreshniks" is a kind of Albanian mythology, for heroes for big sizes, where hyperbolic and metaphor are very common. In the meantime, has served as a subtracts of our creation of Albanian nation).

Now, however, the mentality has changed and being healthy and not obese is the goal. But obesity and eating behavior are vital topics and dealing with them is not easy (Form the past till now the mentality to be big and fat has changed. Now the strategy against overweight and obesity is in children's adults and ages). Genes do not define one's destiny. Genes are not the destination (the study shows that we can change our way of life depending also on other factors as nutrition healthy lifestyle and social health care standards. Obese parents not necessarily give birth to obese children.... heredity goes until $40 \%$ so the case is open to improve the healthy way of our life)
\end{abstract}

\section{Introduction}

There is a close relationship between physical activity, physical fitness, and health in adults [1,2]. Because the onset of many chronic diseases is in early childhood [3], children and youth are critical target groups for preventive intervention. Intervention generally should begin at an early age for two reasons:

1. To ensure normal growth and development [4].

2. To avoid children's lifestyle habits and risk factors persisting through and into their adult life [5-7].

This second reason relates especially to variables like overweight, high blood pressure, physical inactivity, unfavorable lipid profile, and inadequate cardiorespiratory fitness. Although chronic diseases are infrequent in youth, risk factors are present and track from childhood to adult life $[8,9]$. It is difficult to establish specific criteria to define risk in children and adolescents compared with adults. Childhood and adolescent obesity can persist into adulthood [10]. Approximately $20 \%-30 \%$ of the variability in BMI at age 33 years is estimated to be explained by BMI at age 11 or 16 years [11]. An even higher persistence of obesity into adulthood is found in children with severe obesity and those with overweight/obese parents [11]. In addition, high BMI in adolescence is predictive of adult mortality [12]. Since childhood obesity is a strong predictor of adult obesity, it is paramount to prevent the development of obesity in the first place.

It is now generally accepted that bodyweight before the age of 6 years has very limited predictive power for the occurrence of overweight or obesity in adulthood, regardless of 
family history of obesity. The excessively sedentary behavior poses a risk for overweight in adults, and the technological revolution of the late 20th century (electronic games, TV, mobiles and I pad are more and more frequented from children. Using cars and public transport has created a vicious circle of immobility), is one of the prime causes of the epidemic of obesity in affluent nations [13].

Study shows that the decrease in habitual physical activity levels brought on by the electronic/technological revolution, increased affluence, and the popularity of home entertainment may represent the most rapid evolutionary challenge that humans have been forced to confront, and that the epidemic of obesity represents one of the grade-shifts in species morphology that occur from time to time in response to an overwhelming change in the external environment [13].

\section{The Current Epidemic of Obesity and Inactivity}

The World Health Organization has tentatively recommended the use of BMI for age as an indicator of overweight or obesity [14]. Although BMI may not be a very precise indicator of adiposity, many studies have supported its use as an indicator of fatness for larger populations $[15,16]$. Obesity and physical inactivity, which leads to weight gain, are two of the most prevalent risk factors for common chronic diseases. Obese individuals are generally very sedentary, as their excess body mass prevents them from adopting a more physically active lifestyle. The energy expenditure from physical activity is thus too low for most people to be able to eat normally without having to be on caloric restriction diets from time to time or having to be constantly retraining their food intake. It has been estimated that the current deficit of energy expenditure from physical activity compared to that of the recent past ranges on average from 300 to $800 \mathrm{kcal} /$ day $[17,18]$.

Obese individuals can normalize their metabolic risk profile by regular physical activity compared with sedentary healthy normolipidemic controls while still being obese from a bodycomposition standpoint [19]. The modern lifestyle has led to a decrease in overall energy expenditure. Leisure time activities now include more sedentary activities, such as video games, television, and movies [20]. The resulting positive energy balance is probable a significant contributor to the current rise in the prevalence of obesity. Studies on the genetics of obesity have revealed that the increase in the prevalence of obesity is only partly due to genetically determined factors [21] and that the modern lifestyle is responsible for much of the positive energy balance.

Weight loss by a hypo caloric diet decreases lipolysis and fat oxidation, thereby predisposing individuals to weight regain. The blunted utilization of fat as fuel during a 60-min bout of exercise at 50\% VO2 max contributes to a positive fat balance and possibly weight gain in formerly obese individuals [22].

\section{Nutrition and Basal Metabolic Rate}

Like any other machine, the body needs energy to work. However, the body's energy requirements are complicated by one basic reality: Unlike automobiles or vacuum cleaners, the body is alive. We must realize that the body is really a cooperative colony of trillions of cells, each of which has its own existence and energy need. It takes fuel for these cells to produce more than 100,000 chemicals. In the past, the genetic factor was largely attributed to bad eating habits of obese parents, which supposedly determined the food choices of their children. However, an early study measuring resting metabolic rate (RMR) and energy intake in 3-4-year-old children found that children with at least one obese parent consumed less energy but also expended less energy, especially in physical activity, than those with no obese parents [23].

In addition, studies show that fat babies do not necessarily become fat adults. The fat-cell theory (that fat babies develop more fat cell, thereby causing adult obesity) has been disproved by $\mathrm{Dr}$ Alexander F. Roche of Fels Research Institute in Yellow Spring, OH. Obesity experts believe that fatness, which appears early, is the hardest to deal with because even if weight is lost, the cells do not decrease in number; they merely become emptied of some of their reserves and are always ready to enlarge again.

At the age of 10-11, which included and our study, is another critical period for the multiplication of storage cells. However, if a person becomes obese after about the age of 20 years, the number of cells does not increase (we have just cellular hypertrophy), individual cells merely enlarge (we have hyperplasia) [24]. RMR is the energy expended by a subject resting in bed in the morning in a fasting state under comfortable, ambient conditions. RMR includes the cost of maintaining the integrated system of the body and the homoeothermic temperature at rest. In most sedentary adults, RMR accounts for approximately $60 \%-70 \%$ of daily energy expenditure [25].

The weight is one indicator of the status of our fat storage, but it can be a deceptive indicator, especially given the wide variation in human body size and composition. Activity habits are established at a young age; studies on intervention strategies in adults show that those people who can most readily be persuaded to take up more activity are those who were physically active as children [26]. Some crude evidence suggests that the reduction in energy expenditure in children and adults is the most important determinant of overweight, and it is not difficult to see that major changes in lifestyle have occurred in youngsters over the last few decades [27]. Weight loss reduces blood pressure, improves lipid profile, and reduces the risk of diabetes [28].

\section{Conclusion}

The reality of nutrition is both personal and universal; they are in some way always unique, and in some way always the same. The modern lifestyle is one of responsible factors that we burn less calorie per day. Exercise can be one of the treatments against excess body weight and combined with a proper diet. Basal metabolic rate changes with age reflecting an increase of fatness, a decline in muscle, a change in the function of two sets of glands (thyroid and adrenals), or other factors or combination of factors. However, contrary to popular belief, experimental evidence shows that 
fatter persons do not have an unusually active appetite, find taste extremely stimulating, or have very different patterns of appetite.

\section{Practical Implications}

1. There is a complex relationship between personal, lifestyle, and environmental parameters that influence the risk for cardiovascular disease.

2. Certain genetic factors and metabolism are associated with body size and shape, body fat distribution, and metabolic rate. If both parents are overweight, their children are twice as likely to be overweight as children who have only one overweight parent.

3. Other studies have compared the weight of adopted children to those of their biological parent and adoptive parent and found that the strongest correlation is to the biological parent.

4. Working with children and youth requires a special approach due to the wide differences that are seen within and between diverse sex and age groups as both growth and heredity affect the relationships being studied.

5. What is needed to prevent overweight and obesity is a series of major policies aimed at transforming our environment and the way we live. City planning, building codes, mass transit system, car use safe footpaths, and cycling paths, pedestrianonly city center, school schedules and programs, and the media are among the areas that will require transformation.

6. The challenge for public health professionals is to spread the message of physical activity to the majority of the population, who have not yet understood the damage that the modern sedentary lifestyle is doing to their health.

7. It necessary to create a National Obesity Task Force for preventing the future problem of our society in correlation with the International Obesity Task Force (IOTF).

\section{Perspectives}

We can say at least that the contribution of genetic factors to body weight and environmental factors also play a role. Not all the children of obese parents become obese and normal-weight parents also have overweight children. Weight loss or gain also affects metabolic rate in the meantime both heredity and behavior affect too. Exercise has a positive effect on their metabolism in terms of increased RMR. Exercise also increases their fat-free mass, which is associated with a higher metabolic rate. The exercise itself burns calories, raising total energy expenditure. The higher the energy expenditure, the more the child can eat without gain weight. Weight loss can be achieved and maintained; it requires ongoing commitment. Because positive energy balance is a prerequisite for weight gain, dietary habits play a key role in the prevalence of overweight and obesity. The new national curricula do not include measurement anthropometrics. Prevention of obesity should be among the high priorities in public health. This prevention should certainly include encouraging healthy lifestyles in all age groups, including children and adolescents. This cannot be achieved by efforts aimed at the individual level. Communities, governments, the media, and the food industry need to work together to modify the environment to make it less conducive to gain weight.

\section{References}

1. Ness AR, Powles JW (1997) Fruit and vegetables, and cardiovascular disease: a review. Int J Epidemiol 26 (1): 1-13.

2. US Department of Health and Human Services (1996) Physical activity and health: A report of the surgeon general. U.S. Department of Health and Human Services, Centers for Disease Control and Prevention, National Center for Chronic Disease Prevention and Health Promotion, USA, pp. 1-277.

3. Berenson GS, Srinivasan SR, and Nicklas TA (1998) Atherosclerosis: a nutritional disease of childhood. Am J Cardiol 82(10B): 22T-9T.

4. Malina RM, Bouchard C (1991) Physical activity as a factor in growth, maturation, and performance. growth, maturation, and physical activity. ( $2^{\text {nd }}$ edn), Human Kinetics, Champaign, Illinois, USA, pp. 371-90.

5. Andersen LB, Haraldsdottir J (1993) Tracking of cardiovascular disease risk factors including maximal oxygen uptake and physical activity from late teenage to adulthood. An 8-year follow-up study. J Intern Med 234(3): 309-315.

6. Berenson GS, McMahan CA, Voors AW (1980) Cardiovascular risk factors in children: The Bogalusa heart study. Oxford University Press, Oxford, USA.

7. Kemper HC, Snel J, Verschuur R, Storm-van EL (1990) Tracking of health and risk indicators of cardiovascular diseases from teenager to adult: Amsterdam Growth and Health Study. Prev Med 19(6): 642-655.

8. Goran MI, Malina RM (1999) Fat distribution during childhood and adolescence: implications for later health outcomes. Am J Hum Biol 11(2): 187-188

9. Rolland-Cachera MF, Bellisle F, Deheeger M, Pequignot F, Sempe M (1990) Influence of body fat distribution during childhood on body fat distribution in adulthood: a two-decade follow-up study. Int J Obes Relat Metab Disord 14(6): 473-481.

10. Andersen LB (1996) Tracking of risk factors for coronary heart disease from adolescence to young adulthood with special emphasis on physical activity and fitness. A longitudinal study. Dan Med Bull 43(5): 407-418.

11. Power C, Lake JK, Cole TJ (1997) Body mass index and height from childhood to adulthood in the 1958 British born cohort. Am J Clin Nutr 66(5): 1094-1101.

12. Engeland A, Bjorge T, Sogaard AJ, Tverdal A (2003) Body mass index in adolescence in relation to total mortality: 32-year follow-up of 227,000 Norwegian boys and girls. Am J Epidemiol 157(6): 517-523.

13. Prentice AM (1997) Obesity-the inevitable penalty of civilization? British Medical Bulletin 53(2): 229-237.

14. WHO (1995) Physical status: the use and interpretation of anthropometry WHO Technical report Series \#854. WHO Geneva.

15. Deurenberg P, Westrate JA, Seidell JC (1991) Body mass index as a measure of body fatness: age - and sex - specific prediction formulas. British Journal of Nutrition 65(2): 105-114.

16. Pietrobelli A, Faith MS, Allison DB, Gallagher D, Ciumello G, et al. (1998) Body mass index as a measure of adiposity among children and adolescents: a validation study. Journal of Pediatrics 132(2): 204-210

17. James WPT (1995) A public health approach to the problem of obesity. International Journal of Obesity 19: S37-S45.

18. Schoeller DA, Shay K, Kushner RF (1997) How much physical activity is needed to minimize weight gain in previously obese women? American Journal of Clinical Nutrition 66(3): 551-556. 
19. Anonymous (1990) Position stand on "The recommended quality and quality of exercise for developing and maintaining cardiorespiratory and muscular fitness in healthy adults:" Med Sci Sports Exerc 22(2): 265-274.

20. McGinnis JM (1992) The public health burden of a sedentary lifestyle Medicine and Science in Sport and Exercise 24(Suppl 6): S196-S200.

21. Bouchard C, Despres JP, Mauriege P (1993) Genetic and non genetic determinants of regional fat distribution. Endocrinology Review 14(1): 72-93.

22. Ranneries C, Bulow J, Bueman B, Christensen NJ, Madsen J, et al. (1998) Fat metabolism in formerly obese women. American Journal of Physiology 274: E155- E161.

23. Griffiths M, Payne PR (1976) Energy expenditure in small children of obese and non-obese parents. Nature 260(5553): 698-700.
24. Endocrine and metabolic adaptations to obesity. Summary 7, Vol. I Obesity in Perspective, DHEW Pub. No (NIH)75-708,197.

25. Jequier E, Schutz Y (1983) Long-term measurements of energy expenditure in humans using a respiratory chamber. American Journal of Clinical Nutrition 38(6): 989-998.

26. James WPT (1995) A public health approach to the problem of obesity. International Journal of Obesity and Related Metabolic Disorders 19 (Suppl 3): S37-S43.

27. Jebb SA (1997) Aetiology of obesity. British Medical Bulletin 53: 264285.

28. Sjostrom CJ, Lissner L, Sjostrom L (1997) Relationship between changes in body composition and changes in cardiovascular risk factor. The SOS Intervention Study. Obesity Research 5(6): 519-530. 